\title{
Sourcing Metals in Seafloor Hydrothermal Systems: A Research Legacy of Steve Scott
}

MARK D. HANNINGTON ${ }^{1,2 *}$

${ }^{1}$ GEOMAR Helmholtz Centre for Ocean Research Kiel,

24148 Kiel, Germany (*mhannington@geomar.de)

${ }^{2}$ Earth and Environmental Sciences, University of Ottawa, K1N 6N5 Canada

The question of metal sources in seafloor hydrothermal systems is a central theme in the research legacy of Steve Scott, from the laboratory to the Kuroko deposits of Japan and ore deposits on the ocean floor. Key to identifying the major geological controls on sources, sinks and transport pathways of metals in the oceans has been the exploration of different volcanic and tectonic settings of seafloor mineralization. In the early $1990 \mathrm{~s}$, all mid-ocean ridge (MOR) black smoker deposits were considered to be very much alike, but new discoveries in other settings showed a remarkable diversity of deposit types with different metal associations and different controls on mineralization that underpin our current model of VMS. Chief among these are the role of arc magmas in delivering metals to convective hydrothermal systems that are already producing VMS, the role of metal-enriched continental crust (especially sediments) in the path of convecting hydrothermal fluids, the abundance of magmatic sulfides available for leaching from mafic and ultramafic source rocks, boiling as a precipitation mechanism at both high and low temperatures (and pressures), previously unrecognized diagenetic processes and subseafloor metal enrichment, the likelihood of metal transport at concentrations that greatly exceed maximum calculated solubilities (e.g., as nanoparticle suspensions), and the possibility of deep fluid reservoirs that are tapped periodically to produce the largest and most metal-rich deposits. These different scenarios will be examined in a range of modern seafloor settings, from mid-ocean ridges, hot spot volcanoes, intraoceanic subduction zones and arc stratovolcanoes, major arc rifts and back-arc spreading centers, rifted continental margins and related sedimentary basins, and seafloor "mega" calderas. Steve Scott's pioneering work on land and in the oceans endures as the inspiration to explore these diverse settings for seafloor mineral deposits. 